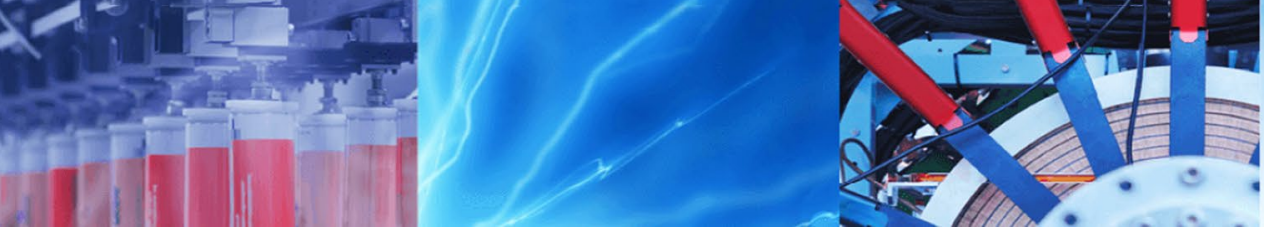

Research Article

\title{
High-temperature storage deterioration behaviors of lithium-ion batteries using nickel-rich cathode and $\mathrm{SiO}-\mathrm{C}$ composite anode
}

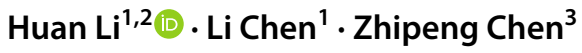

Received: 3 February 2020 / Accepted: 19 May 2020 / Published online: 28 May 2020

(c) Springer Nature Switzerland AG 2020

\begin{abstract}
The deterioration behaviors of the lithium-ion pouch full cells consisted of Ni-rich $\mathrm{LiNi}_{0.8} \mathrm{Co}_{0.1} \mathrm{Mn}_{0.1} \mathrm{O}_{2}(\mathrm{NCM} 811)$ cathode and $\mathrm{SiO}-\mathrm{C}$ composite anode after stored at $55^{\circ} \mathrm{C}$ for 7 days were investigated. A significant increase in the interface impedance of the cell and a change in structure of the anode surface passivation films are attributed to constant electrolyte decomposition inducing the regeneration of SEI films, which result in the constant consumption of active lithium source and rapid capacity fading. After high-temperature storage, the initial charge capacity of anode is reduced from 609.1 to $514.3 \mathrm{mAh} \mathrm{g}^{-1}$. Furthermore, the disintegration of NCM811 cathode secondary particle was observed, and after high-temperature storage, the reversible capacity of cathode decreases from 170.6 to $134.9 \mathrm{mAh} \mathrm{g}^{-1}$.
\end{abstract}

Keywords Lithium-ion batteries - Thermal stability - Deterioration behaviors · SiO-C composite anode

\section{Introduction}

Lithium-ion battery (LIB) possesses favorable electrochemical performance, such as outstanding energy density and excellent cycle performance. It has been extensively used in many energy storage devices. However, with the highspeed development of stationary batteries for energy storage systems as well as electric vehicles (EVs) and plug-in hybrid electric vehicles (PHEVs) in recent years, the advanced LIBs modules with lightweight, long-life and high thermal-stable batteries need to be developed.

In terms of lightweight, the LIBs must possess high energy density and the cathode and anode active materials should exhibit high reversible specific capacity and favorable electrochemical performance.

$\mathrm{Ni}$-rich transition metal layered oxides $\left(\mathrm{LiNi}_{x} \mathrm{Co}_{y} \mathrm{Mn}_{1-x-y} \mathrm{O}_{2}\right.$, Ni-rich NCM) possess high reversible specific capacities $\left(>200 \mathrm{mAh} \mathrm{g}^{-1}\right.$ ) which have been spotlighted in recent years [1,2]. The further NCM material research strategy has focused on adjusting the proportion of the nickel content to improve its specific capacity to satisfy the growing demand for battery energy storage applications such as EVs [3, 4].

Silicon monoxide (SiO) exhibits the highest theoretical capacity than graphite $[5,6]$ and slighter volume expansion than Si $[7,8]$; however, SiO shows poor conductivity and the initial coulombic efficiency is unsatisfactory $[9,10]$. Preparing SiO-C composite is an optimal strategy to surmount these intractable problems. The carbon matrix can not only dramatically reduce the volume expansion during the cycling, but enhance the electronic conductivity of SiO significantly $[11,12]$.

Fortunately, we find that the full cell using Ni-rich NCM811 and SiO-C composite possesses high energy density $\left(>300 \mathrm{wh} \mathrm{kg}^{-1}\right)$, indicating that this full cell is a promising substitute to use in battery energy storage applications. However, this electrochemical system shows a fragile

$\triangle$ Huan Li, lihuan@stu.ouc.edu.cn | 1 Institute of Engineering Research, Hefei Guoxuan High-Tech Power Energy CO., Ltd., Hefei 230011, China. ${ }^{2}$ College of Chemistry and Chemical Engineering, Ocean University of China, Qingdao 266100 , China. ${ }^{3}$ Qingdao Institute of Bioenergy and Bioprocess Technology, Chinese Academy of Sciences, Qingdao 266101, China. 
thermal stability, which is considered as fatal defect for the large-scale application of high energy density LIBs [13, 14].

In this work, we concentrate on the thermal stability of full cells consisted of Ni-rich NCM811 and SiO-C composite. It is found that the full cell shows a significant capacity fade and obviously increased in the interfacial impedance after stored at $55^{\circ} \mathrm{C}$ for 7 days. The NCM811 cathode and the $\mathrm{SiO}-\mathrm{C}$ composite anode before and after high-temperature storage are investigated through SEM, XRD, CV and $\mathrm{EIS}$ analysis. The causes of the deterioration phenomena were discussed.

\section{Experimental}

\subsection{Preparation of cathode}

97.5 wt\% NCM811 powders (Rongbay New Energy Technology Co., Ltd.) were used as the cathode active material, $1.5 \mathrm{wt} \%$ polyvinylidene fluoride (PVDF) (Solvay, 5130) was served as the binder and $1 \mathrm{wt} \%$ carbon nanotubes (CNTs) were used as conductive agent.

\subsection{Preparation of anode}

Anodes were prepared using a mixture of SiO-C composite (BTR New Energy Materials Inc.), carbon black (Super P), synthetic conductive graphite (KS-6) and water-soluble binder in the weight ratios of 91:2:1:6. Deionized water was used as the solvent.

The both-sides coated anodes and cathodes were sealed in an aluminum-polymer pouch films. The full cells were vacuum-filled with electrolyte composed of $1 \mathrm{M}$ $\mathrm{LiPF}_{6}$ in EC:DEC:EMC:FEC (2:2:5:1 in volume ratio) with 1 $\mathrm{wt} \%$ vinylene carbonate (VC). Cells were galvanostatically cycling at $1 / 3 \mathrm{C}$ current rate between 2.5 and $4.2 \mathrm{~V}$. Hightemperature storage tests were carried out at charged states $(4.2 \mathrm{~V})$ for 7 days at $55^{\circ} \mathrm{C}$.

\subsection{Physical characterization}

Sample structure morphology and elemental composition were analyzed by scanning electron microscopy (SEM, FEI NOVA NANOSEM 450) and EDS, respectively. The sample crystal structure was performed using $X$-ray diffraction (XRD, Philips $X^{\prime}$ Pert PRO MPD) with $\mathrm{Cu}-\mathrm{K}_{a}$ radiation $(\lambda=1.5406 \mathrm{~nm})$.

\subsection{Electrochemical diagnostics}

The unstored and stored pouch full cells were disassembled in Ar-atmosphere glove box and the electrodes were cleaned in dimethyl carbonate (DMC). After dried in vacuum, the electrodes were assembled in coin cells in Ar-atmosphere glove box using the Li-metal foils as the counter electrodes and reference electrodes.

Herein, the fresh anodes were represented by $\mathrm{SC} 1$ and the anodes after high-temperature storage test were represented by SC2. The CV tests were recorded on a Solartron SI1287/1260 analyzer at $0.1 \mathrm{mV} \mathrm{s}^{-1}$ scanning rate. The NCM811/SiO-C full cells and coin cells for EIS measurements were carried out on $4.2 \mathrm{~V}$ and $0.2 \mathrm{~V}$, respectively and relaxed for $12 \mathrm{~h}$ before test.

\section{Results and discussion}

\subsection{NCM811/SiO-C full cell}

Figure 1a depicts the room temperature charge/discharge curves of the pouch full cell for the 1st, 2 nd and 3rd cycles at a current rate of $1 / 3 \mathrm{C}$. The full cell delivers reversible capacities of 7.61, 7.56, 7.52 Ah at the 1st, 2nd and 3rd cycles, respectively.

The (dQ/dV) plot (Fig. 1b) of full cell before high-temperature storage test, where capacity is represented by $Q$ and voltage is represented by $V$, observed a distinct reductive peak at $4.0 \mathrm{~V}$ and two relatively weak reductive peaks at 3.7 and $3.2 \mathrm{~V}$. However, after high-temperature storage, no conspicuous peak shift was identified except for an unobvious peak at $3.9 \mathrm{~V}$ from the $(\mathrm{d} Q / \mathrm{d} V)$ plots, which manifests the deterioration of the electrode active materials and the decreased peak currents arise from sluggish solid-state diffusion-related reaction between lithium-ions and electrode active materials [15].

The Nyquist plots of full cells are shown in Fig. 1c. The equivalent circuit is used to model the EIS of the unstored and stored full cells. In the equivalent circuit, $R_{1}$ is the electrolyte and separator resistances. The capacitance and the solid-electrolyte interface (SEI) films resistance are expressed by $C_{1}$ and $R_{2}$, respectively, which correspond to the high-frequency semicircle. $C_{2}$ represents the doublelayer capacitance and the $R_{3}$ is the charge transfer resistance, corresponding to the medium frequency semicircle. The straight sloping line represents the diffusion of lithium-ion within the electrodes, corresponding to the Warburg impedance at low frequency, expressed by $W[16,17]$.

After high-temperature storage test, the $R_{1}$ of full cell increases from 4.10 to $14.14 \mathrm{~m} \Omega$ and the $R_{2}$ of full cell increases from 2.15 to $30.25 \mathrm{~m} \Omega$. It implies that the electrolyte is decomposed on the surface of electrode materials during the high-temperature storage process, the regeneration of SEl films will lead to an irreversible Li consumption, which causes a significant capacity fade (capacity retention at $1 / 3 \mathrm{C}$ is about $36 \%$ ) [18-20]. The $R_{3}$ values of the full cell before high-temperature storage and 

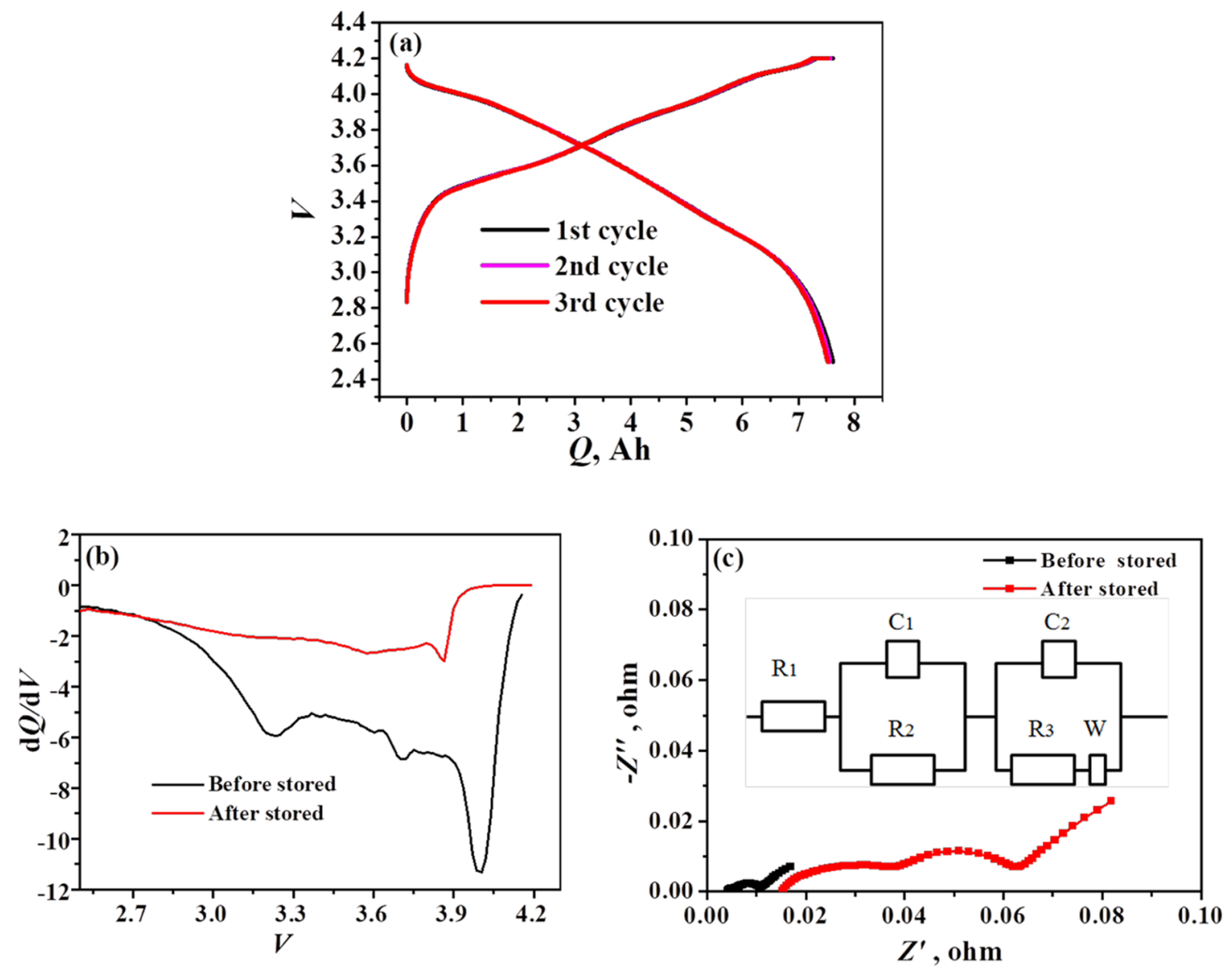

Fig. 1 a Room temperature charged/discharged curves of full cell at $1 / 3 \mathrm{C} ; \mathbf{b}$ The $(\mathrm{d} Q / \mathrm{d} V$ ) plots for the second discharge of the unstored and stored full cell; c Nyquist plots of unstored and stored full cell

high-temperature stored full cell are calculated to be 4.34 and $15.97 \mathrm{~m} \Omega$, respectively, showing an obvious growth of the charge transfer resistance. The degeneration of the ionic transmission path caused by the changes of interface films and electrodes structures as well as the obstruction of electronic transmission path caused by the deteriorated of solid-liquid interface will result in the aggravation of the electrode kinetics $[18,20]$.

\subsection{NCM811 cathode}

The XRD patterns of unstored and stored cathodes are shown in Fig. 2a. The cathode materials manifest typical pattern of $a-\mathrm{NaFeO}_{2}$ layered structure with $R \overline{3} \mathrm{~m}$ space group. In particular, the (006/102) and (108/110) splitting peaks also can be identified, which indicate that the cathode samples have an ordered layer structure [21, 22]. The XRD pattern shows no additional reflections in the stored materials, suggesting that no obvious crystal structural changes occur during high-temperature storage test. Figure $2 b$ shows the charged/discharged curves of cathode between 2.75 and $4.3 \mathrm{~V}$ at $190 \mathrm{~mA} \mathrm{~g}^{-1}$. The discharge capacity of fresh cathode and stored cathode is 170.6 and $134.9 \mathrm{mAh} \mathrm{g}^{-1}$, respectively, showing a capacity decreasing after high-temperature storage test.

Figure $3 a, b$ shows the SEM images of cathode before and after high-temperature storage test. As exhibited in Fig. 3a, the NCM811 secondary particles keep a spherical morphology. However, there is disintegration of NCM811 secondary particles after high-temperature storage test (Fig. 3b). The suppress pressure during calendering has important effect on the fracture of NCM811 secondary particles. The attached small particles on the surface of stored cathode are more likely to be broken product of secondary particles. It also has been suggested that the activity and evolution of oxygen in NCM materials, particularly at charged state and under extreme thermal environments, can directly impact the chemo-mechanical stability. The phase transformation caused by release of oxygen generates partial stresses, which can potentially result in the chemo-mechanical deterioration [23, 24]. Otherwise, the disintegration of cathode secondary particles can also 

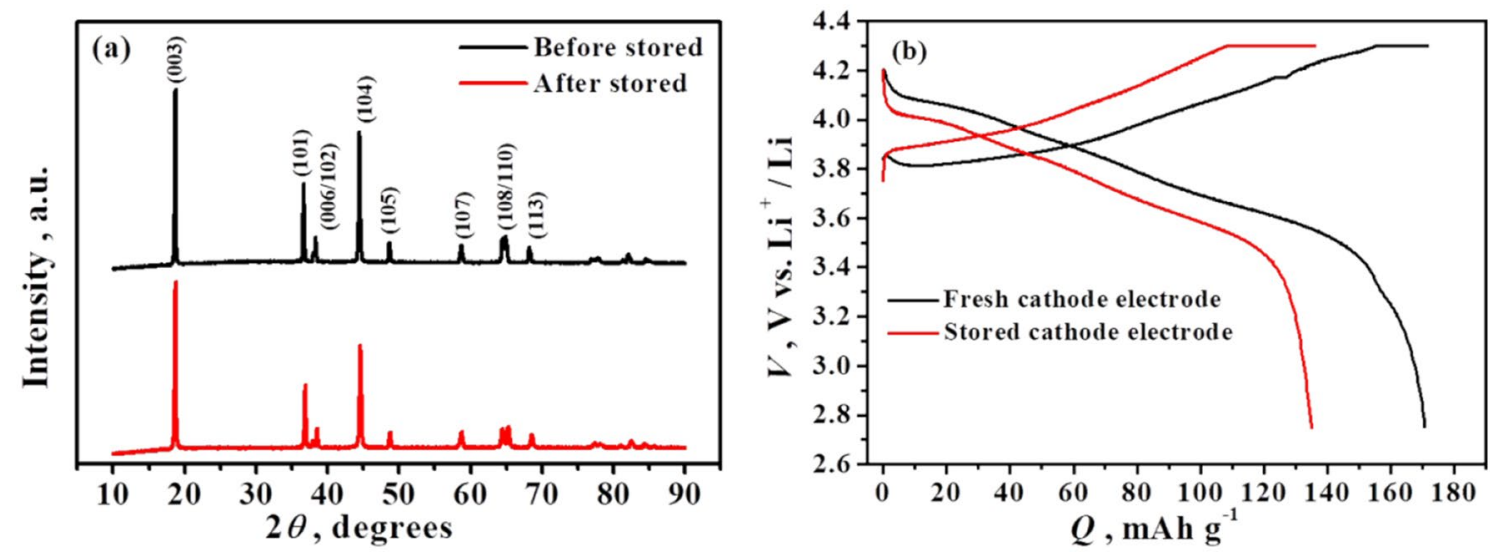

Fig. 2 a XRD patterns of unstored and stored cathodes; $\mathbf{b}$ Charged/discharged curves of fresh cathode and stored cathode
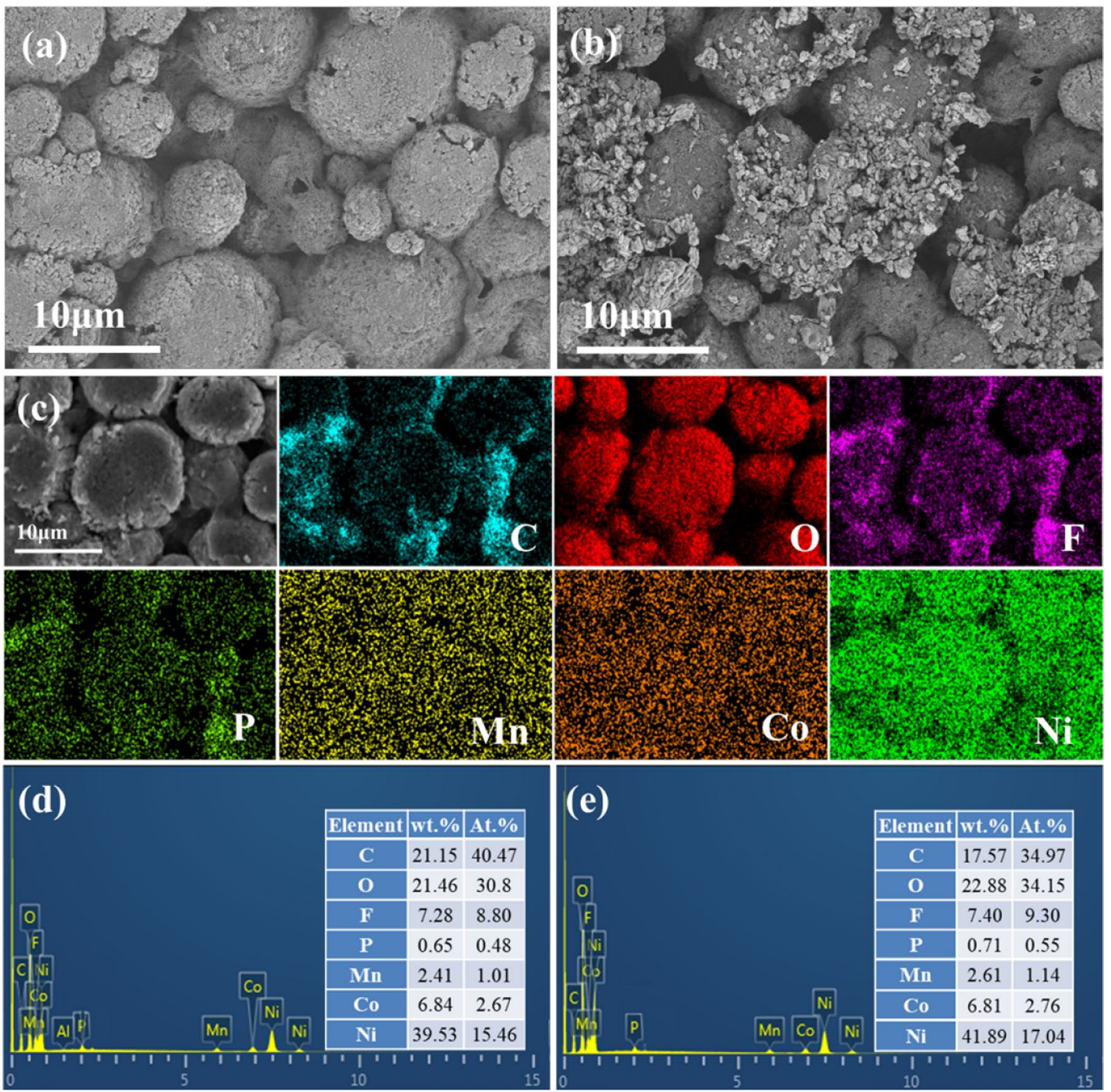

Fig. 3 SEM images of unstored cathodes (a) and stored cathodes (b); $\mathbf{c}$ the corresponding elemental mapping images of carbon, oxygen, fluorine, phosphorus, manganese, cobalt and nickel of the stored cathode; EDS spectra of $\mathbf{d}$ unstored and e stored cathodes

\section{SN Applied Sciences}


lead to the increase in specific surface area, which aggravates the decomposition of the electrolyte, promoting the dissipation of the active lithium source in the cathode active materials. The elemental mapping images of stored cathode are exhibited in Fig. 3c, and the EDS spectra of the cathode are exhibited in Fig. 3d, e. It is found that the atomic percentage of $\mathrm{F}, \mathrm{O}$ and $\mathrm{P}$ of stored cathode is higher than that of unstored cathode. The above result reveals that decomposed adducts of NCM particles surface are ascribed to the decomposition of electrolyte and lithium salts.

Thus, the mechanical strength of NCM secondary particles should be taken into account in the processes of materials preparation and the single crystal of $\mathrm{Ni}$-rich cathode material is a better selection.

\subsection{SiO-C composite anode}

Figure 4a presents the charged/discharged curves of SC1 and SC2 between 0.05 and $1.5 \mathrm{~V}$ at a current density of $30 \mathrm{~mA} \cdot \mathrm{g}^{-1}$. The initial charge capacity of SC1 and SC2 is 609.1 and $514.3 \mathrm{mAh} \mathrm{g}^{-1}$, respectively, showing a significant capacity fading after high-temperature storage test. The capacity retentions of SC 1 and SC2 after 100 cycles at current density of $30 \mathrm{~mA} \cdot \mathrm{g}^{-1}$ are $65.6 \%$ and $53.1 \%$, respectively (Fig. 4b). It indicates that the specific capacity and cycle stability of stored anode are deteriorated, which may be caused by the aggravation of the electrode kinetics due to degeneration of the ionic transmission path caused by the changes of interface films.

Figure 4c presents the first cycle of CV curves of SC1 and $\mathrm{SC2}$, respectively. It should be noted that a slight irreversible reduction peak can be observed at near $1.1 \mathrm{~V}$, which is attributed to the reduction of the FEC on the electrodes surface $[25,26]$, and the reduction peak detected at $0.02 \mathrm{~V}$ is ascribed to the electrochemical Li-alloying reactions and the lithium-ions intercalation into carbon materials $[27,28]$. The $R_{2}$ of SC2 $(17.86 \Omega)$ is higher than that of the SC1 $(1.80 \Omega)$, which implies that the constant electrolyte decomposition induces the regeneration of SEI films on the surface of anode materials during the hightemperature storage process. We can speculate that the main reasons for capacity fading are originated from the continuous dissipation of lithium inventory caused by the degeneration of the SEl films.

The XRD patterns of SiO-C composite samples are exhibited in Fig. $5 \mathrm{~g}$. The results show that $\mathrm{SiO}-\mathrm{C}$ composite anodes exhibit several clear peaks at $26.6^{\circ}, 50.4^{\circ}$,
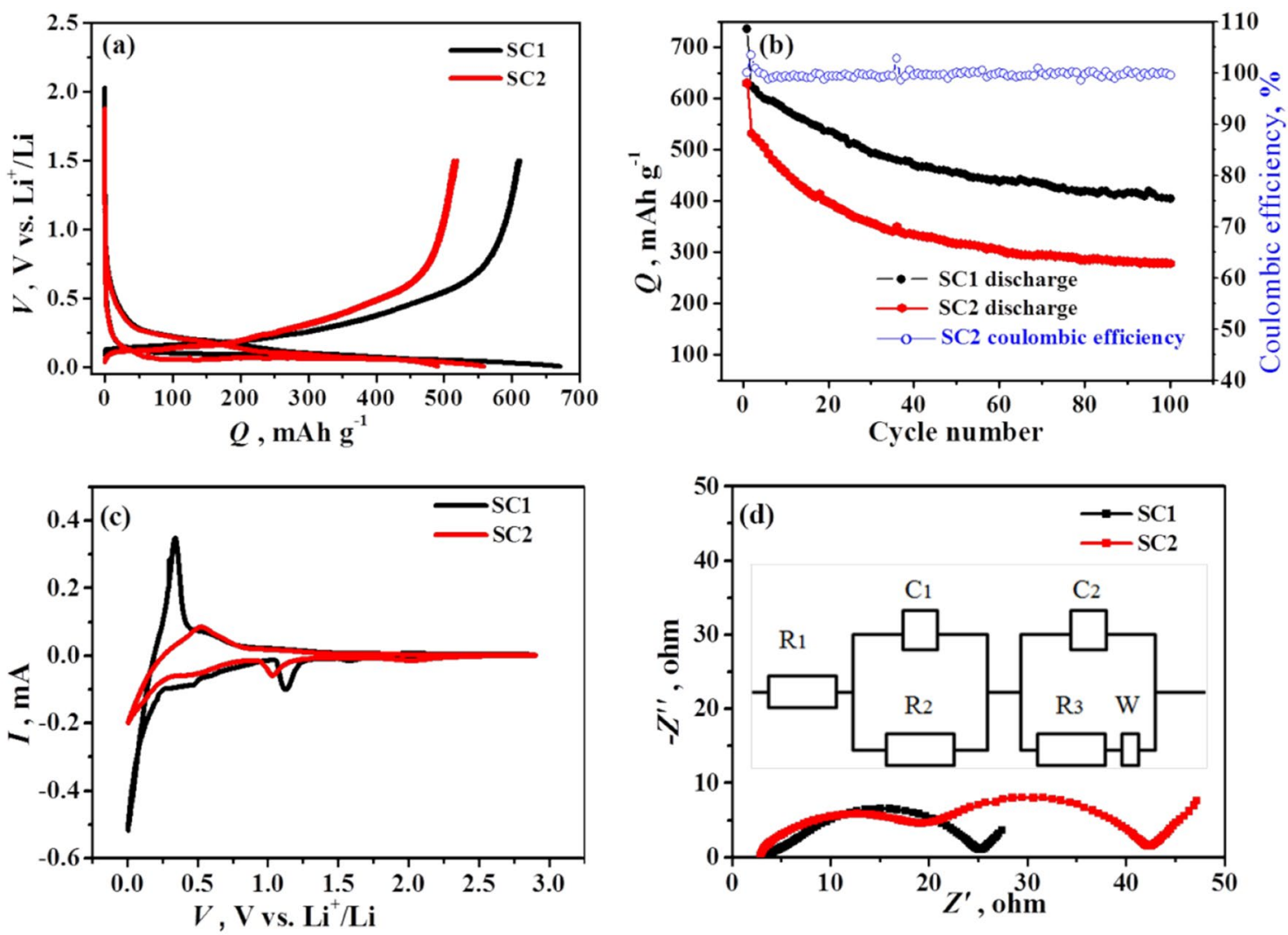

Fig. 4 a Galvanostatically charged/discharged curves of SC1 and SC2; b Cycle stability of SC1 and SC2; c The CV curves of SC1 and SC2 at 0.1 $\mathrm{mV} \mathrm{s}{ }^{-1} ; \mathbf{d}$ Nyquist plots of SC1 and SC2 
Fig. 5 SEM images of a fresh SiO-C composite, $\mathbf{b}$ unstored anode, c stored anode and d cross section of the stored anode; EDS spectrum of $\mathbf{e}$ unstored and $\mathbf{f}$ stored anode; $\mathbf{g}$ XRD patterns of unstored and stored anode
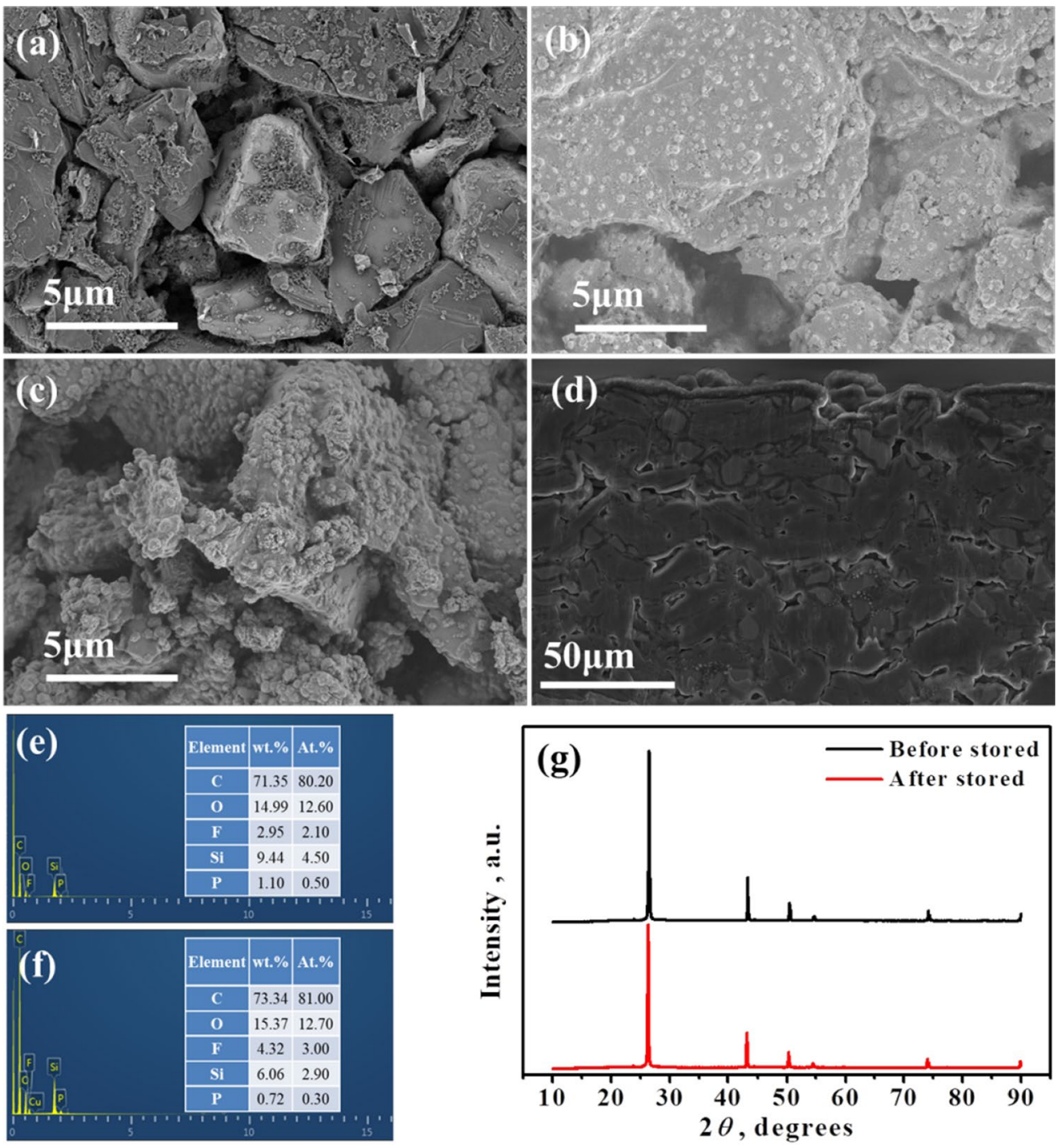

$54.9^{\circ}$, and $74.3^{\circ}$, which correspond to the (111), (220), (311) and (331) lattice orientations of $\mathrm{Si}$, respectively [29]. The two diffraction peaks at approximately $23^{\circ}$ and $43^{\circ}$ are originated from the (002) and (100) planes of the carbon materials [30]. These peaks were not observed in the bare $\mathrm{SiO}$ spectrum, suggesting that $\mathrm{SiO}$ consists of nanocrystalline $\mathrm{Si}$ and amorphous silicon oxide [31]. The XRD results imply that there is no significant structural collapse of SiO-C composite anode during high-temperature storage process.

As shown in Fig. 5a, the $\mathrm{SiO}$ particles are embed in the carbon matrix and the carbon acts as a buffer area for volume expansion of $\mathrm{SiO}$ during the cycling and employed as an electrical conducting medium. It is known that the SEI films are formed on anode of full cell in the initial charge cycle, which corresponds to an activation process [32]. Figure $5 \mathrm{~b}$ represents the $\mathrm{SEM}$ of $\mathrm{SiO}-\mathrm{C}$ composite anode before high-temperature storage test. We can observe that the loose and porous SEI film was formed on the surface of SiO-C composite anode after the initial charge cycle.
The morphology of anode after high-temperature storage (Fig. 5c, d) shows a significant difference from that of unstored one (Fig. 5b). Figure $5 c$, d shows that the surface of stored anode consisted of the paste-like decomposed adduct, which originates from constant electrolyte decomposition inducing the regeneration of SEl films, due to the electrolyte would penetrate through the less dense and porous SEI film into the active material for further decomposition during high-temperature storage process.

The elemental mapping images (Fig. 6) and EDS spectra (Fig. 5e, f) of the stored anode show that the decomposed adduct generated on the surface of anode consists mainly of $\mathrm{F}$ and $\mathrm{P}$ elements, and the atomic percentage of $\mathrm{F}$ is increased significantly, proving the electrolyte decomposed on the surface of SiO-C composite. The results from the SEM and the EDS are in coincidence with the EIS tests of the stored anode, confirming the deterioration of the electrode/electrolyte interphase.

Furthermore, we think that the loose and porous SEI layer structure (Fig. 5b) generated on the surface of the 
Fig. 6 a SEM images of stored anode; $\mathbf{b}-\mathbf{f}$ the corresponding elemental mapping images of silicon, carbon, oxygen, fluorine, phosphorus of stored anode
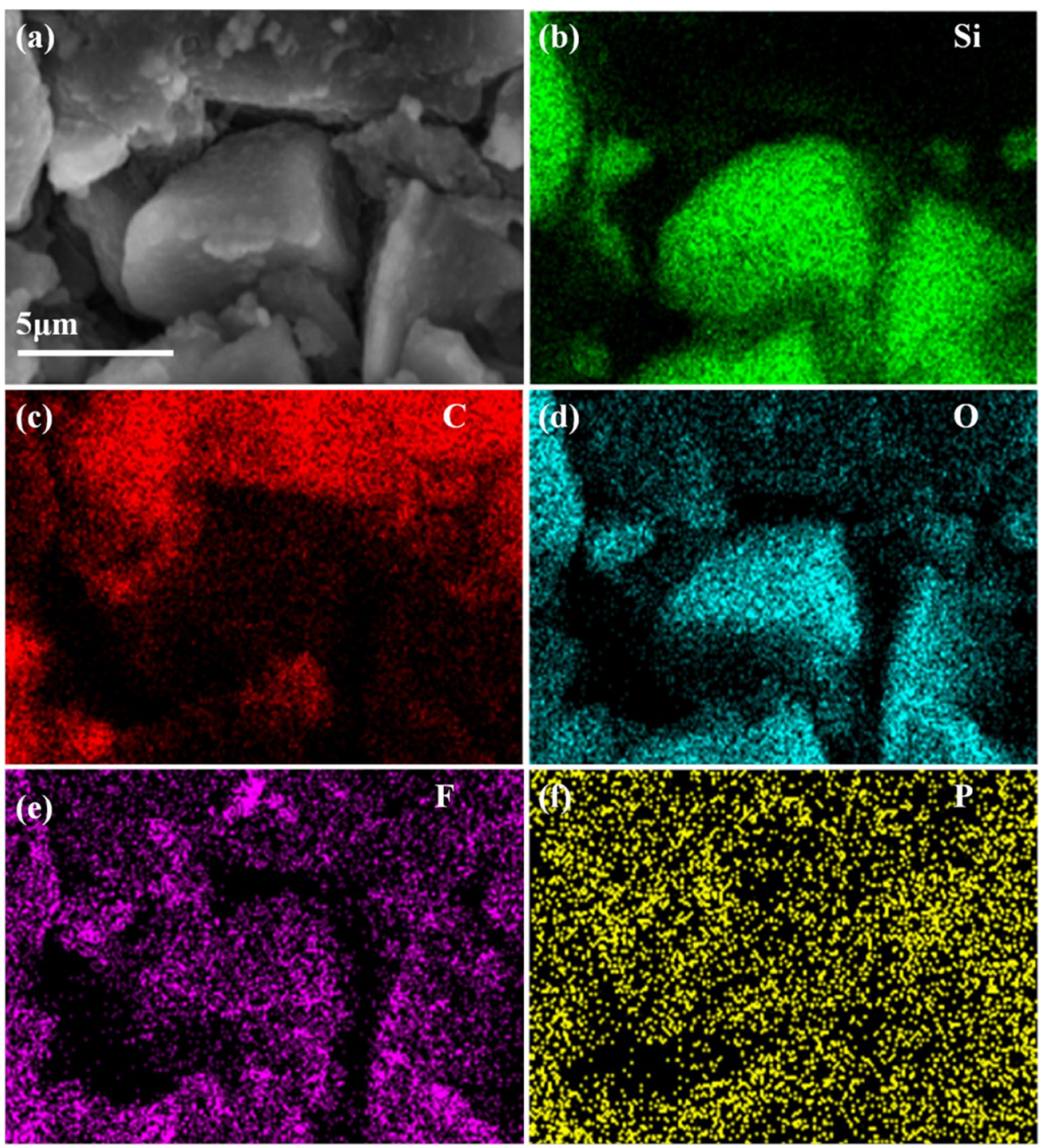

anode possesses fragile thermal stability, and the SEI films will be degenerated and regenerated during hightemperature storage process. However, if a compact SEI film is constructed, the electrolyte molecules would not penetrate through SEI layer into the active material for further decomposition, thereby suppressing continual regeneration of the SEI film. In comparison, we report a homogeneous and compact SEI film by modified the electrolyte additives.

Figure $7 \mathrm{a}-\mathrm{c}$ presents the SEM and elemental mapping images of stored anode of modified full cell, we can observe that a homogeneous and compact SEI film was formed on the surface of anode, which is obviously different from that of SC2 (Fig. 5b). Significantly, after hightemperature storage test, the modified full cell can deliver a capacity retention of $88.5 \%$ at $1 / 3 \mathrm{C}$ (Fig. $8 \mathrm{a}$ ), which is favorable compared to the full cell with loose and porous SEl film structure (capacity retention at $1 / 3 \mathrm{C}$ is about $36 \%)$, showing superior thermal stability. The $R_{1}, R_{2}, R_{3}$ of modified full cell increase from $2.95,2.03,3.04 \mathrm{~m} \Omega$ to $3.86,2.37,5.60 \mathrm{~m} \Omega$ after high-temperature storage test (Fig. 8b); the resistances increasing have been improved dramatically, proving the excellent thermal stability of the compact SEI film structure.

\section{Conclusions}

In this work, the fragile thermal stability mechanisms of this full cell were investigated carefully. Specifically, the NCM811 secondary particles are found to be disintegrated after high-temperature storage test. The loose and porous SEI layer structure generated on the surface of the anode possesses fragile thermal stability. In addition, the constant electrolyte decomposition inducing the regeneration of SEl films on the surface of SiO-C composite anode during high-temperature storage process, would give rise to the degeneration of the 

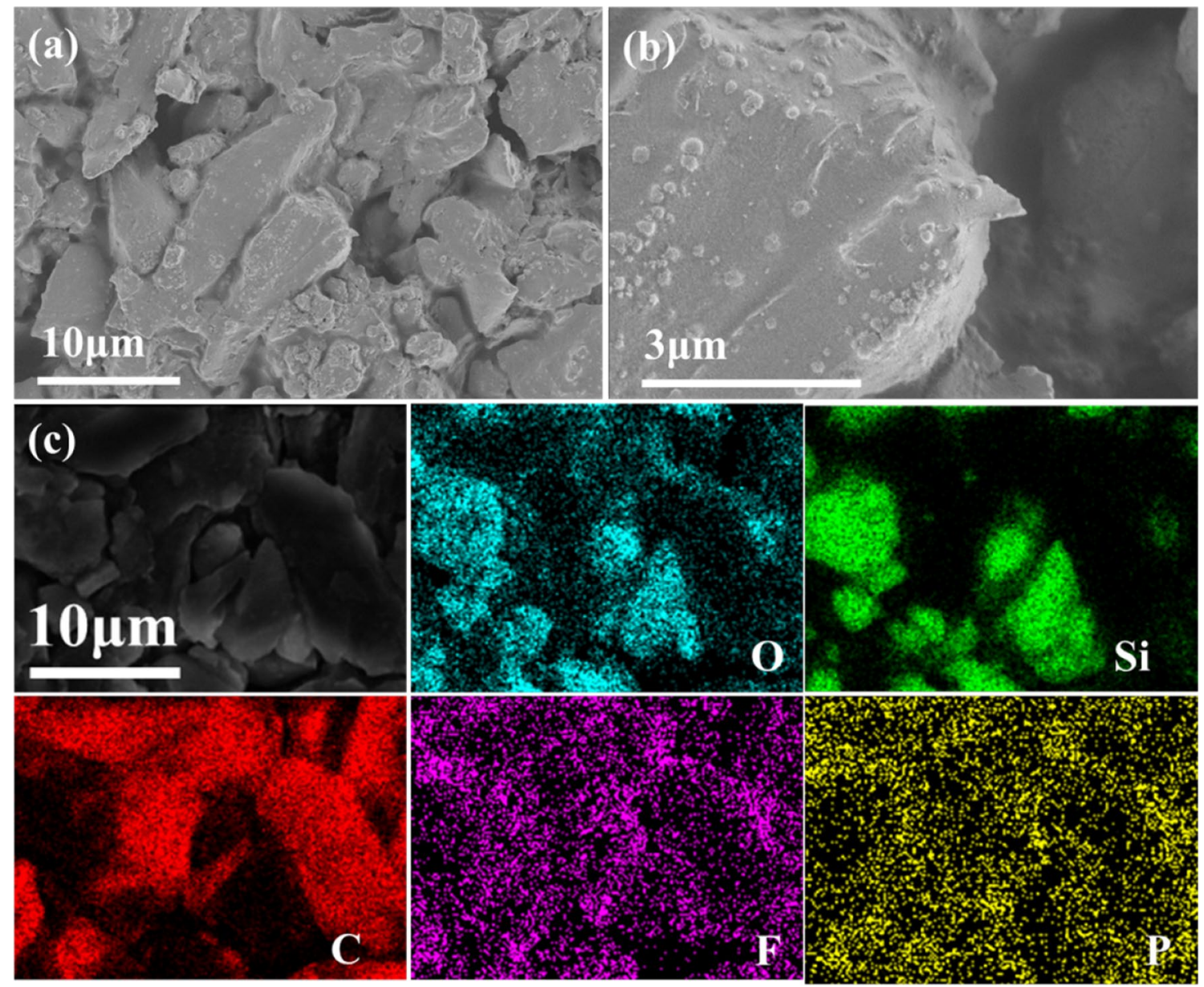

Fig. 7 a, b SEM images of stored anode of modified full cell; c the corresponding elemental mapping images of silicon, carbon, oxygen, fluorine, phosphorus of stored anode of modified full cell
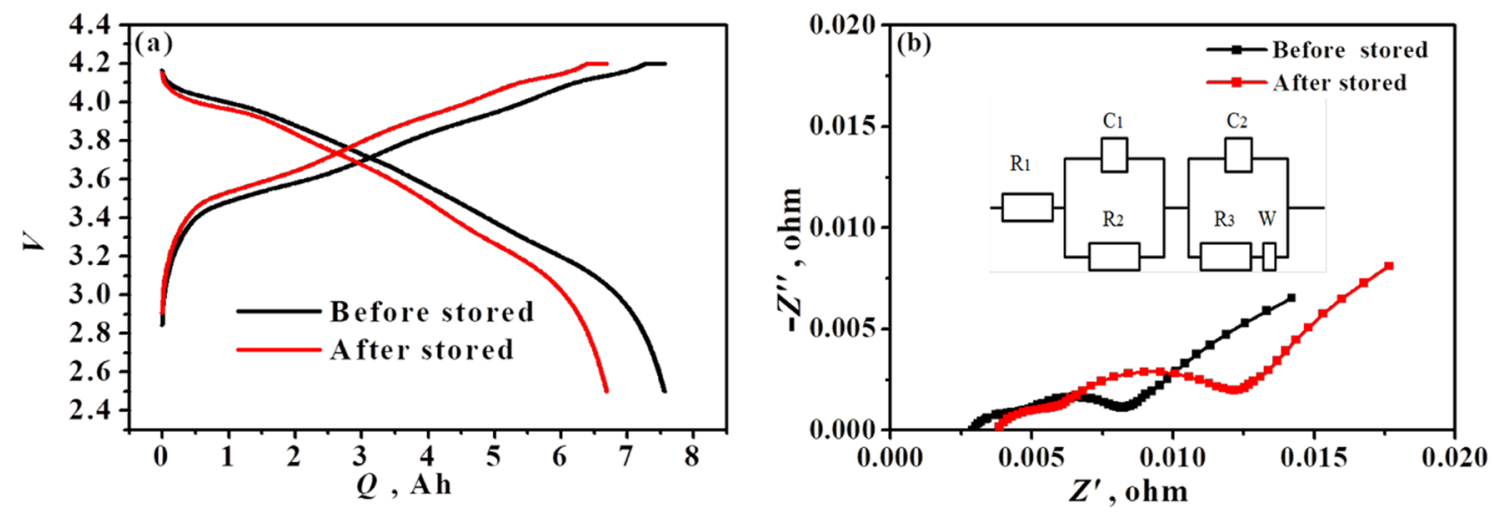

Fig. 8 a Galvanostatically charged/discharged curves of the unstored and stored modified full cell; b Nyquist plots of unstored and stored modified full cell

electrode/electrolyte interphase, which are confirmed by SEM, EDS and EIS. The disintegration of cathode materials and deterioration of anode/electrolyte interphase cause the electrochemical performance of full cells deterioration after high-temperature storage. Collectively, our findings emphasize the importance of the compact SEI layer structure and further suggest paying more attention to the chemo-mechanical stability of

\section{SN Applied Sciences}


NCM secondary particles when designing future high energy density cathode materials.

Acknowledgements This work was supported by National Key R\&D Program of China (No. 2016YFB0100306).

\section{Compliance with ethical standards}

Conflict of interest The authors declare that they have no conflict of interest.

\section{References}

1. Liu W, Oh P, Liu X, Lee MJ, Cho W, Chae S, Kim Y, Cho J (2015) Nickel-rich layered lithium transition-metal oxide for highenergy lithium-ion batteries. Angew Chem Int Ed 54:4440-4457. https://doi.org/10.1002/anie.201409262

2. Sun Y-K, Chen Z, Noh H-J, Lee D-J, Jung H-G, Ren Y, Wang S, Yoon CS, Myung S-T, Amine K (2012) Nanostructured high-energy cathode materials for advanced lithium batteries. Nat Mater 11:942. https://doi.org/10.1038/nmat3435

3. Armand M, Tarascon J-M (2008) Building better batteries. Nature 451:652. https://doi.org/10.1038/451652a

4. Dunn B, Kamath H, Tarascon J-M (2011) Electrical energy storage for the grid: a battery of choices. Science 334:928-935. https:// doi.org/10.1126/science.1212741

5. Shi L, Pang C, Chen S, Wang M, Wang K, Tan Z, Gao P, Ren J, Huang Y, Peng H (2017) Vertical graphene growth on SiO microparticles for stable lithium ion battery anodes. Nano Lett 17:3681-3687. https://doi.org/10.1021/acs.nanolett.7b00906

6. Komaba S, Shimomura K, Yabuuchi N, Ozeki T, Yui H, Konno K (2011) Study on polymer binders for high-capacity SiO negative electrode of Li-ion batteries. J Phys Chem C 115:13487-13495. https://doi.org/10.1021/jp201691g

7. Li H, Huang X, Chen L, Wu Z, Liang Y (1999) A high capacity nano $\mathrm{Si}$ composite anode material for lithium rechargeable batteries. Electrochem Solid-State Lett 2:547-549. https://doi. org/10.1149/1.1390899

8. Zhang W-J (2011) Lithium insertion/extraction mechanism in alloy anodes for lithium-ion batteries. J Power Sources 196:877885. https://doi.org/10.1016/j.jpowsour.2010.08.114

9. Wang H, Wu P, Qu M, Si L, Tang Y, Zhou Y, Lu T (2015) Highly reversible and fast lithium storage in graphene-wrapped $\mathrm{SiO}_{2}$ nanotube network. ChemElectroChem 2:508-511. https://doi. org/10.1002/celc.201402370

10. Wu W, Shi J, Liang Y, Liu F, Peng Y, Yang H (2015) A low-cost and advanced $\mathrm{SiO}_{\mathrm{x}}-\mathrm{C}$ composite with hierarchical structure as an anode material for lithium-ion batteries. Phys Chem Chem Phys 17:13451-13456. https://doi.org/10.1039/C5CP01212K

11. Meng J, Cao Y, Suo Y, Liu Y, Zhang J, Zheng X (2015) Facile fabrication of 3D SiO $@$ @graphene aerogel composites as anode material for lithium ion batteries. Electrochim Acta 176:10011009. https://doi.org/10.1016/j.electacta.2015.07.141

12. Yuan Z, Zhao N, Shi C, Liu E, He C, He F (2016) Synthesis of $\mathrm{SiO}_{2} / 3 \mathrm{D}$ porous carbon composite as anode material with enhanced lithium storage performance. Chem Phys Lett 651:1923. https://doi.org/10.1016/j.cplett.2016.03.015

13. Markovsky B, Talyossef Y, Salitra G, Aurbach D, Kim H-J, Choi S (2004) Cycling and storage performance at elevated temperatures of $\mathrm{LiNi}_{0.5} \mathrm{Mn}_{1.5} \mathrm{O}_{4}$ positive electrodes for advanced $5 \mathrm{~V}$ Li-ion batteries. Electrochem Commun 6:821-826. https://doi. org/10.1016/j.elecom.2004.06.005
14. Jeżowski $P$, Crosnier $O$, Deunf E, Poizot $P$, Béguin $F$, Brousse $T$ (2018) Safe and recyclable lithium-ion capacitors using sacrificial organic lithium salt. Nat Mater 17(2):167. https://doi. org/10.1038/nmat5029

15. Shim J, Kostecki R, Richardson T, Song X, Striebel KA (2002) Electrochemical analysis for cycle performance and capacity fading of a lithium-ion battery cycled at elevated temperature. J Power Sources 112:222-230. https://doi.org/10.1016/S0378 -7753(02)00363-4

16. Cao X, Kim JH, Oh SM (2002) The effects of oxidation on the surface properties of MCMB-6-28. Electrochim Acta 47:4085-4089. https://doi.org/10.1016/S0013-4686(02)00407-3

17. Zhang $S, X u K$, Jow T (2004) Electrochemical impedance study on the low temperature of Li-ion batteries. Electrochim Acta 49:1057-1061. https://doi.org/10.1016/j.electacta.2003.10.016

18. Abraham D, Reynolds E, Sammann E, Jansen A, Dees D (2005) Aging characteristics of high-power lithium-ion cells with $\mathrm{LiNi}_{0.8} \mathrm{Co}_{0.15} \mathrm{Al}_{0.05} \mathrm{O}_{2}$ and $\mathrm{Li}_{4 / 3} \mathrm{Ti}_{5 / 3} \mathrm{O}_{4}$ electrodes. Electrochim Acta 51:502-510. https://doi.org/10.1016/j.electacta.2005.05.008

19. Han X, Ouyang M, Lu L, Li J, Zheng Y, Li Z (2014) A comparative study of commercial lithium ion battery cycle life in electrical vehicle: aging mechanism identification. J Power Sources 251:38-54. https://doi.org/10.1016/j.jpowsour.2013.11.029

20. Wu Z, Cao C, Yan X, Zang X, Zhao Y, Ma X, Liu R, Hu L, Jiang Y, Sun $S$ (2019) Effects of charge cut-off voltage on the performances of monocrystalline $\mathrm{LiNi}_{0.5} \mathrm{Co}_{0.2} \mathrm{Mn}_{0.3} \mathrm{O}_{2}$ /graphite Li-ion cells. Electrochim Acta 302:153-160. https://doi.org/10.1016/j.elect acta.2019.01.181

21. Li J, Li Y, Yi W, Ma P (2019) Improved electrochemical performance of cathode material LiNi0.8Co0.1Mn0.1O2 by doping magnesium via co-precipitation method. J Mater Sci Mater Electron 30(8):7490-7496. https://doi.org/10.1007/s10854-01901062-0

22. Li J, Li Y, Guo Y, Lv J, Yi W, Ma P (2018) A facile method to enhance electrochemical performance of high-nickel cathode material $\mathrm{Li}\left(\mathrm{Ni}_{0.8} \mathrm{Co}_{0.1} \mathrm{Mn}_{0.1}\right) \mathrm{O}_{2}$ via Ti doping. J Mater Sci: Mater Electron 29:10702-10708. https://doi.org/10.1007/s10854-018-9093-1

23. Hu E, Bak S-M, Liu J, Yu X, Zhou Y, Ehrlich SN, Yang X-Q, Nam K-W (2013) Oxygen-release-related thermal stability and decomposition pathways of $\mathrm{Li}_{x} \mathrm{Ni}_{0.5} \mathrm{Mn}_{1.5} \mathrm{O}_{4}$ cathode materials. Chem Mater 26:1108-1118. https://doi.org/10.1021/cm403400y

24. Mu L, Lin R, Xu R, Han L, Xia S, Sokaras D, Steiner JD, Weng T-C, Nordlund D, Doeff MM (2018) Oxygen release induced chemomechanical breakdown of layered cathode materials. Nano Lett 18:3241-3249. https://doi.org/10.1021/acs.nanolett.8b01036

25. Hu YS, Demir-Cakan R, Titirici MM, Müller JO, Schlögl R, Antonietti M, Maier J (2008) Superior storage performance of a Si@ $\mathrm{SiO}_{x} / \mathrm{C}$ nanocomposite as anode material for lithium-ion batteries. Angew Chem Int Ed 47:1645-1649. https://doi.org/10.1002/ anie.200704287

26. Profatilova IA, Stock C, Schmitz A, Passerini S, Winter M (2013) Enhanced thermal stability of a lithiated nano-silicon electrode by fluoroethylene carbonate and vinylene carbonate. J Power Sources 222:140-149. https://doi.org/10.1016/j.jpows our.2012.08.066

27. Guo C, Wang D, Liu T, Zhu J, Lang X (2014) A three dimensional $\mathrm{SiO}_{x} / \mathrm{C} @ \mathrm{RGO}$ nanocomposite as a high energy anode material for lithium-ion batteries. J Mater Chem A 2:3521-3527. https:// doi.org/10.1039/C3TA13746E

28. Yuan X, Xin H, Qin X, Li X, Liu Y, Guo H (2015) Self-assembly of $\mathrm{SiO} /$ reduced graphene oxide composite as high-performance anode materials for Li-ion batteries. Electrochim Acta 155:251256. https://doi.org/10.1016/j.electacta.2014.12.124

29. Lee DJ, Ryou M-H, Lee J-N, Kim BG, Lee YM, Kim H-W, Kong B-S, Park J-K, Choi JW (2013) Nitrogen-doped carbon coating for a high-performance SiO anode in lithium-ion batteries. 
Electrochem Commun 34:98-101. https://doi.org/10.1016/j. elecom.2013.05.029

30. Wang Y-X, Chou S-L, Liu H-K, Dou S-X (2013) Reduced graphene oxide with superior cycling stability and rate capability for sodium storage. Carbon 57:202-208. https://doi.org/10.1016/j. carbon.2013.01.064

31. Kim J-H, Park C-M, Kim H, Kim Y-J, Sohn H-J (2011) Electrochemical behavior of $\mathrm{SiO}$ anode for Li secondary batteries. J Electroanal Chem 661:245-249. https://doi.org/10.1016/j.jelec hem.2011.08.010
32. Araki K, Sato N (2003) Chemical transformation of the electrode surface of lithium-ion battery after storing at high temperature. J Power Sources 124(1):124-132. https://doi.org/10.1016/S0378 $-7753(03) 00593-7$

Publisher's Note Springer Nature remains neutral with regard to jurisdictional claims in published maps and institutional affiliations. 